\title{
Use of response surface methodology to evaluate the reducing power in binary solutions of ascorbic acid with natural polyphenolic antioxidants
}

\author{
Marie Aoun ${ }^{\mathrm{a}}$ AND Dimitris P. MAKRIS ${ }^{\mathrm{b}^{*}}$

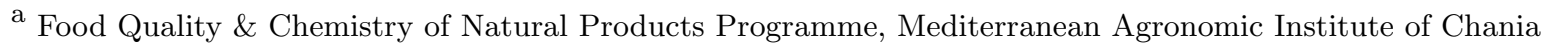 \\ (M. A. I. Ch.), P. O. Box 85, 73100, Chania, Greece \\ ${ }^{\mathrm{b}}$ Department of Food Science \& Nutrition, University of the Aegean, 2, Mitr. Ioakim, 81400, Myrina, Lemnos, \\ Greece \\ ${ }^{*}$ Corresponding author \\ dmakris@aegean.gr
}

Received: 17 February 2013; Published online: 18 October 2013

\begin{abstract}
Natural polyphenols, ferulic acid (FA) and hesperetin (Hp) were tested for their $\mathrm{Fe}^{3+}$-reducing power, using the TPTZ methodology, as a first step to rank them according to their antioxidant potential. Ranking also included quercetin (Qt), a very well-studied natural, polyphenolic antioxidant, and ascorbic acid (AA). All phenolics considered were also tested in binary mixtures with AA, to illustrate possible mixture effects. By employing a simple linear regression approach, combinations of AA / Qt and AA / Hp were shown to result in antagonistic effects, whereas in mixtures of AA / FA, synergism was observed. To thoroughly investigate the role of the relative concentrations of the antioxidants, a $3 \times 3$ factorial design was implemented. This approach enabled the recording of the response (reducing power) upon simultaneous variation of concentrations of both antioxidants in the mixtures, and revealed only antagonism for every combination tested. It is proposed that in similar investigations factorial designs need to be implemented for reliable prediction of the antioxidant response(s) within appropriate limits. This is particularly crucial for antioxidants that are destined to be added in food matrices, where maximal antioxidant protection is always sought.
\end{abstract}

Keywords: Ascorbic acid; ferulic acid; hesperetin; reducing power; response surface methodology 


\section{Nomenclature}

$\begin{array}{ll}\text { AA } & \text { Ascorbic acids } \\ \text { FA } & \text { Ferulic acid } \\ \text { Hp } & \text { Hesperetin } \\ \text { ME } & \text { Mixture effect } \\ \mathrm{P}_{R} & \text { Reducing power } \\ \text { Qt } & \text { Quercetin }\end{array}$

\section{Introduction}

Oxidative deterioration is a major concern with regard to consumer acceptability of foods, because of the generation of off-flavours, loss of essential nutrients and production of potentially toxic components (Choe \& Min, 2009). The addition of exogenous antioxidants or extracts containing antioxidants (Krishnaiah, Sarbatly, \& Nithyanandam, 2011) to foods, in addition to inherent substances possessing antioxidant properties, is believed to provide effective protection against oxidation, by inhibiting or delaying the relevant reactions implicated. Lipophilic antioxidants, such as butylated hydroxytoluene (BHT), have been a tool of preference in this regard, owing to their efficiency and low cost. On the other hand, consumer demands for healthier foods with functional properties, as well as the strong evidence provided for plausible toxicity of synthetic additives, has shifted industrial interest towards antioxidants of natural origin, including polyphenolic substances (Pokorny, 2007).

An important issue arising from the use of such compounds, is their actual efficiency in protecting the substrates occurring in foods, such as proteins and lipids. Phenomena of synergism and antagonism among the various forms of polyphenolic substances are common in foods (Choe \& Min, 2009) and therefore the antioxidant effects emerging by enhancing a given food in antioxidant additives might not be those anticipated. Such behaviours entail a multilateral assessment of the antioxidant activity, instead of simply evaluating the antioxidant status established in a food after addition of antioxidant(s).

The examinations of the antioxidant efficiency of a mixture of antioxidants is usually based on measurements of standard proportions (e.g. 1:1, $2: 1$ etc.) but the effects of varying simultaneously the content of both compounds should also be considered. This is important because the antioxidant effects exerted might be the consequence of an ideal ratio. Deviations from this ratio may bring about undesirable results, since an antioxidant system, under certain circumstances, might switch to prooxidant, with detrimental effects (Kessler, Ubeaud, \& Jung, 2003). Since the antioxidants added are consumed in redox reactions occurring in foods with time, such deviations are to be expected. Thus, variations in the concentration of various antioxidants co-existing in foods could reveal an overall image of the antioxidant efficiency, even when one antioxidant is consumed at the expense of another.

In this context, this investigation was undertaken to obtain an insight into the antiradical and reducing behaviour of two phenolic antioxidants, ferulic acid and hesperetin, in relation with their interactions with a well-studied, non-phenolic antioxidant, ascorbic acid (Fig. 1). Ferulic acid and hesperetin were chosen because, apart from their abundance in food matrices of plant origin (Clifford, 2000; Tomas-Barberen \& Clifford, 2000), both compounds can potentially be produced from cheap sources, such as cereal (Benoit et al., 2006; Tilay, Bule, Kishenkumar, \& Annapure, 2008) and citrus (Di Mauro, Fallico, Passerini, \& Maccarone, 2000; Londono-Londono et al., 2010) by-products and wastes, respectively. For comparison, parallel experiments were also run with quercetin, which is a very powerful polyphenolic antioxidant, with well-established properties (Prochazkova, Bousova, \& Wilhelmova, 2011). 
<smiles>O=C1O[C@H]([C@@H](O)CO)C(O)=C1O</smiles>

(1)<smiles>COc1cc(/C=C/C(=O)O)ccc1O</smiles>

(2)<smiles>COc1cc([C@H]2CC(=O)c3c(O)cc(O)cc3O2)ccc1O</smiles>

(3)

(4)

Figure 1: Chemical structures of the natural antioxidants used in this study. Assignments: (1), ascorbic acid; (2), ferulic acid; (3), quercetin; (4), hesperetin.

\section{Materials and Methods}

\section{$2.1 \quad$ Chemicals}

Quercetin, hesperetin, ferulic acid, ascorbic acid and 2,4,6-tripyridyl- $s$-triazine (TPTZ) were from Sigma (St. Louis, MO, U.S.A.) and ferric chloride $\left(\mathrm{FeCl}_{3} \cdot 6 \mathrm{H}_{2} \mathrm{O}\right)$ was from Merck (Darmstadt, Germany).

\subsection{Reducing Power $\left(\mathrm{P}_{R}\right)$ Assay}

The methodology of Makris, Boskou, and Andrikopoulos (2007) was used to determine $\mathrm{P}_{R}$ of the mixtures and individual components. An aliquot of $0.05 \mathrm{~mL}$ sample was mixed with 0.05 $\mathrm{mL} \mathrm{FeCl}_{3}$ solution $(4.25 \mathrm{mM}$ in $0.06 \mathrm{~N} \mathrm{HCl})$, and incubated for $30 \mathrm{~min}$ in a water bath at $37{ }^{\circ} \mathrm{C}$. Following this, $0.9 \mathrm{~mL}$ TPTZ solution $(1.07 \mathrm{mM}$ in $0.06 \mathrm{~N} \mathrm{HCl}$ ) was added, and the absorbance was recorded at $620 \mathrm{~nm}\left(\mathrm{~A}_{620}\right)$ after exactly 5 $\min$.

\subsection{Determination of Mixture Effect (ME)}

According to Peyrat-Maillard, Cuvelier, and Berset (2003), the mixture effect (ME) of two antioxidants could be defined as the experimental value, divided by the calculated value, which is the sum of the effects of the two antioxidants obtained individually. This can be calculated using equation 1 . If this ratio is $>1$, then it can be said that synergism is observed, whereas a ratio $<1$ would reveal antagonism. In the case of the $\mathrm{P}_{R}$ assay, this could be mathematically expressed as:

$$
\mathrm{ME}=\frac{A_{620}^{A A / P A}}{A_{620}^{A A}+A_{620}^{P A}}
$$

where PA, is the polyphenolic antioxidant.

\subsection{Implementation of linear regression analyses}

For single-antioxidant solutions, the response $\left(\mathrm{A}_{620}\right)$ was plotted against concentration of pure antioxidants, and the linear equation, as well as the coefficient of determination $\left(R^{2}\right)$ drawn 


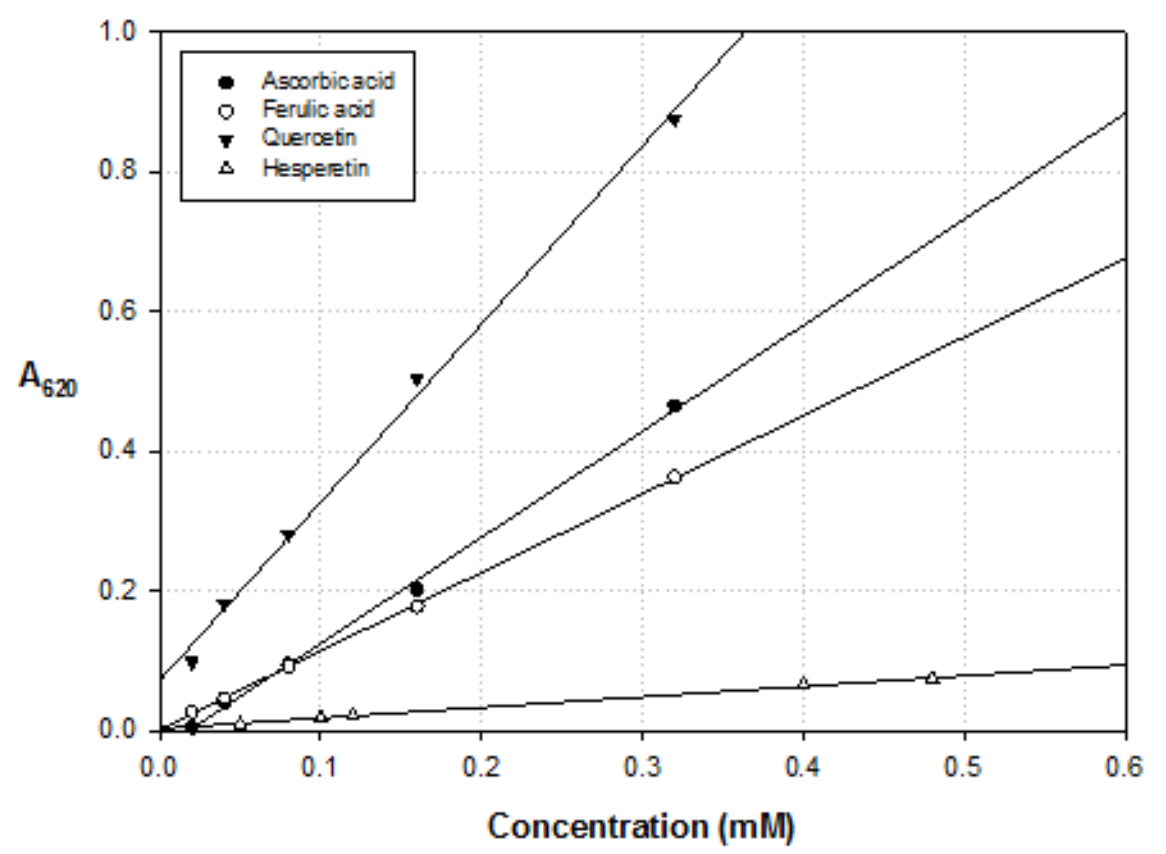

Figure 2: Linear regression between the response $\left(\mathrm{A}_{620}\right)$ and the concentration of single-antioxidant solutions.

from simple linear regression analyses were calculated (Table 1). For the solutions of antioxidant mixtures, responses were plotted against the total antioxidant concentration of the solutions (Fig. 3), which consisted of equimolar amounts of ascorbic acid and either ferulic acid (FA), quercetin (Qt) or hesperetin (Hp). In all cases, the concentration ranges used were those within which linearity was best maintained $\left(R^{2}\right.$ $>0.99$ ), (Table 2).

\subsection{Implementation of $3 \times 3$ factorial design}

A $3 \times 3$ factorial experiment design was used to identify the relationship existing between the response function $\left(\mathrm{A}_{620}\right)$ and variables (concentration of ascorbic acid and polyphenolic antioxidants), as well as to determine those conditions that optimised the response. The two independent variables or factors used were i) ascorbic acid concentration and ii) polyphenolic antioxidant concentration.

For each pair AA / FA, AA / Hp and AA / Qt, concentrations were coded at three levels, as shown in Table 3. For each independent variable, the experimental range was based on the results of preliminary experiments. The independent variables were coded according to the following equation:

$$
x_{i}=\frac{X_{i}-X_{0}}{\Delta X_{i}}, i=1,2
$$

where $\mathrm{x}_{i}$ and $\mathrm{X}_{i}$ are the dimensionless and the actual value of the independent variable $\mathrm{i}, \mathrm{X}_{0}$ the actual value of the independent variable $i$ at the central point, and $\Delta \mathrm{X}_{i}$ the step change of $\mathrm{X}_{i}$ corresponding to a unit variation of the dimensionless value. The response function at each design point was recorded (Tables 4 - 6). One-way ANOVA permitted the checking of the statistical significance of the regression coefficients deriving from the model. The response surface plot was 


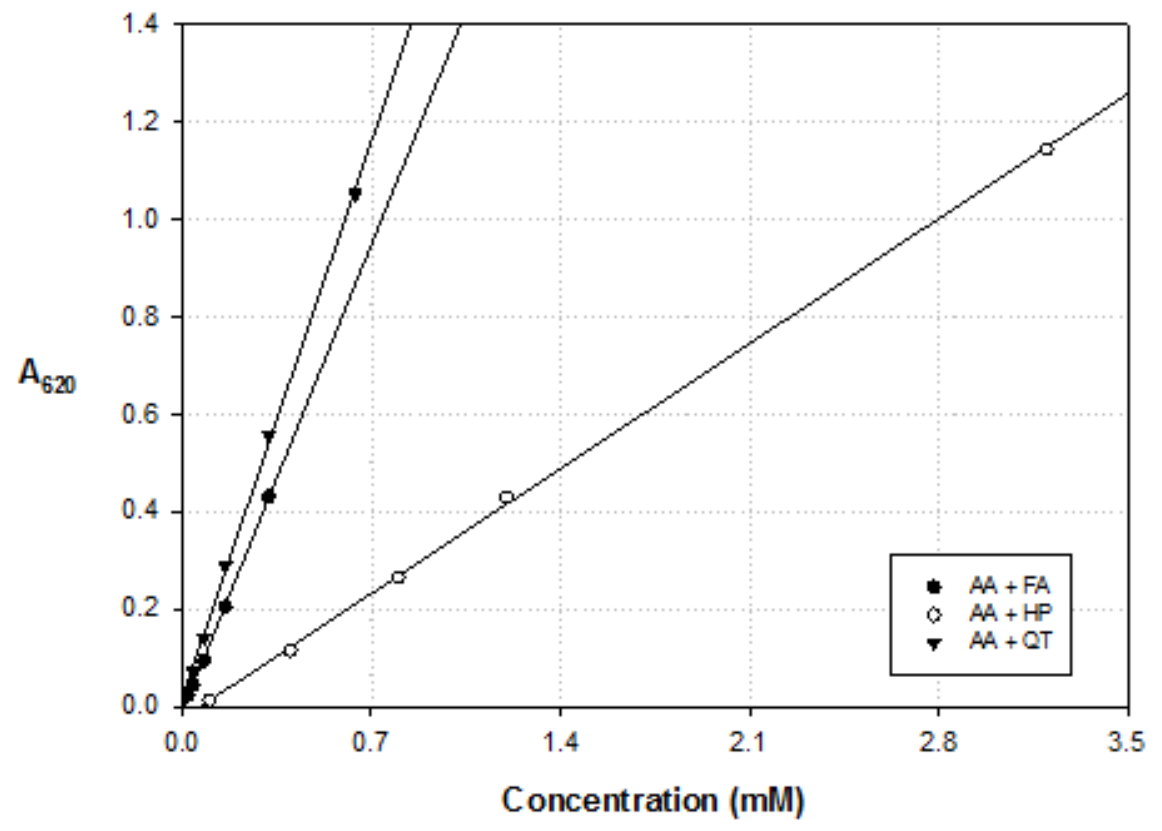

Figure 3: Linear regression between the response $\left(\mathrm{A}_{620}\right)$ and the concentration of solutions of antioxidant mixtures. Values on $\mathrm{x}$ - axis represent the total concentration of the equimolar amounts of the antioxidants in the solution (e.g. concentration of $0.5 \mathrm{mM}$ corresponds to a solution containing $0.25 \mathrm{mM}$ $\mathrm{AA}$ and $0.25 \mathrm{mM}$ of a polyphenolic antioxidant).

Table 1: Concentration ranges, regression equations and $R^{2}$ values from simple linear regression of $A_{620}$ against concentration of single-antioxidant solutions.

\begin{tabular}{lcll}
\hline Compound & Concentration range $(\mathbf{m M})$ & Equation & $\mathbf{R}^{2}$ \\
\hline Ascorbic acid & $0.02-0.32$ & $\mathrm{y}=1.52 \mathrm{x}-0.03$ & 0.998 \\
Quercetin & $0.02-0.32$ & $\mathrm{y}=2.55 \mathrm{x}+0.07$ & 0.996 \\
Ferulic acid & $0.02-0.32$ & $\mathrm{y}=1.12 \mathrm{x}+0.00$ & 0.999 \\
Hesperetin & $0.05-0.48$ & $\mathrm{y}=0.15 \mathrm{x}+0.00$ & 0.998 \\
\hline
\end{tabular}

Table 2: Concentration ranges, regression equations and $\mathrm{R}^{2}$ values from simple linear regression of $\mathrm{A}_{620}$ against concentration of solutions of antioxidant mixtures.

\begin{tabular}{lcll}
\hline Compound & Concentration range $(\mathbf{m M})$ & Equation & $\mathbf{R}^{2}$ \\
\hline $\mathrm{AA}+\mathrm{FA}$ & $0.02-0.32$ & $\mathrm{y}=1.37 \mathrm{x}-0.01$ & 0.999 \\
$\mathrm{AA}+\mathrm{HP}$ & $0.10-3.20$ & $\mathrm{y}=0.37 \mathrm{x}-0.02$ & 0.999 \\
$\mathrm{AA}+\mathrm{QT}$ & $0.04-0.64$ & $\mathrm{y}=1.63 \mathrm{x}+0.02$ & 0.999 \\
\hline
\end{tabular}


Table 3: Experimental values and coded levels of the independent variables used for the $3 \times 3$ factorial design.

\begin{tabular}{lcccc}
\hline Independent variables & Code units & \multicolumn{3}{c}{ Coded variable level } \\
\hline & & $\mathbf{- 1}$ & $\mathbf{0}$ & $\mathbf{1}$ \\
\cline { 3 - 5 } FA / AA Mixture & & & & \\
{$[\mathrm{AA}] / \mathrm{mM}$} & $X_{1}$ & 0.02 & 0.14 & 0.26 \\
{$[\mathrm{FA}] / \mathrm{mM}$} & $X_{2}$ & 0.02 & 0.14 & 0.26 \\
& & & & \\
$H p / A A$ Mixture & & & & \\
{$[\mathrm{AA}] / \mathrm{mM}$} & $X_{1}$ & 0.05 & 0.30 & 0.55 \\
{$[\mathrm{Hp}] / \mathrm{mM}$} & $X_{2}$ & 0.02 & 0.14 & 0.26 \\
& & & & \\
$Q t / A A$ Mixture & & & & \\
{$[\mathrm{AA}] / \mathrm{mM}$} & $X_{1}$ & 0.02 & 0.14 & 0.26 \\
{$[\mathrm{Qt}] / \mathrm{mM}$} & $X_{2}$ & 0.02 & 0.14 & 0.26 \\
\hline
\end{tabular}

obtained using the fitted model, by keeping the independent variables simultaneous.

\subsection{Statistical analyses}

All experimental determinations $\left(\mathrm{P}_{R}\right.$ measurement of individual components and mixtures) were carried out at least in triplicate and values were averaged. For all statistics, SigmaPlot ${ }^{\mathrm{TM}} 11$ (Systat Software Inc, San Jose, California) and $\mathrm{JMP}^{\mathrm{TM}} 8$ (SAS, Cary, New York) were used.

\section{Results}

\subsection{Linear regression approach}

The first of this study step was to rank the selected antioxidants with regard to their antioxidant power, herein the $\mathrm{P}_{R}$ assay. As can be seen in Fig. 2, and taking into account the slopes of the linear relationships produced (Table 1), the order was as follows:

$$
\mathrm{Qt}>\mathrm{AA}>\mathrm{FA}>\mathrm{Hp}
$$

In order to clarify the relationships underlying interactions of the polyphenolic antioxidants with AA, a hypothesis was set up. Using the equations in Table 1 , it could be calculated that 0.1 $\mathrm{mM}$ of Qt, AA, FA and $\mathrm{Hp}$ would yield $\mathrm{A}_{620}$ of $0.325,0.122,0.112$ and 0.015 , respectively. In addition, a mixture of $0.1 \mathrm{mM} \mathrm{AA}$ and $0.1 \mathrm{mM} \mathrm{Qt}$ would theoretically result in $\mathrm{A}_{620}=0.447(0.325$ $+0.122)$, with the corresponding values for AA / FA and AA / Hp being 0.234 and 0.137. On the other hand, using the equations in Table 2, the $\mathrm{A}_{620}$ values for mixtures of $\mathrm{AA} / \mathrm{Qt}, \mathrm{AA} / \mathrm{FA}$ and AA / Hp with total concentration $0.2 \mathrm{mM}$ would be $0.346,0.264$ and 0.054 , respectively. It can be noted that for mixtures of AA / Qt and AA / Hp the ME values, calculated using the equation (1), were 0.77 and 0.39 , respectively, which clearly points to antagonism. By contrast, for mixtures of AA / FA, ME = 1.13, suggesting a synergistic effect.

\subsection{Factorial design approach}

The experimental values of $\mathrm{A}_{620}$ were analysed by multiple regression to fit the second-order polynomial equations shown in Table 7 and the quality of fit was ascertained using the coefficients of determination $\left(R^{2}\right)$. The experimental values showed a good fit with the equations, which were statistically significant at least at $95 \%$ significance level $(p<0.05)$. There was a satisfactory agreement between observed and predicted responses and that the equations were found to adequately predict the experimental results. The utilisation of the predictive models enabled the theoretical calculation of the optimal sets of conditions, within predetermined concentration ranges, under which maximal $\mathrm{A}_{620}$ could be attained (Table 8 ). The trends revealed in 
Table 4: Measured and predicted $\mathrm{A}_{620}$ values of FA / AA mixtures, determined for individual design points.

\begin{tabular}{ccccc}
\hline Design point & \multicolumn{2}{c}{ Independent variables } & \multicolumn{2}{c}{ Response $\left(\mathbf{A}_{620}\right)$} \\
\hline & $\mathbf{X}_{1}$ & $\mathbf{X}_{2}$ & Observed & Predicted \\
\cline { 2 - 5 } 1 & -1 & -1 & 0.041 & 0.017 \\
2 & -1 & 1 & 0.261 & 0.255 \\
3 & 1 & -1 & 0.214 & 0.222 \\
4 & 1 & 1 & 0.280 & 0.310 \\
5 & -1 & 0 & 0.110 & 0.139 \\
6 & 1 & 0 & 0.310 & 0.269 \\
7 & 0 & -1 & 0.115 & 0.122 \\
8 & 0 & 1 & 0.310 & 0.285 \\
9 & 0 & 0 & 0.210 & 0.206 \\
10 & 0 & 0 & 0.194 & 0.206 \\
\hline
\end{tabular}

Table 5: Measured and predicted $\mathrm{A}_{620}$ values of $\mathrm{Hp} / \mathrm{AA}$ mixtures, determined for individual design points.

\begin{tabular}{ccccc}
\hline Design point & \multicolumn{2}{c}{ Independent variables } & \multicolumn{2}{c}{ Response $\left(\mathbf{A}_{620}\right)$} \\
\hline & $\mathbf{X}_{1}$ & $\mathbf{X}_{2}$ & Observed & Predicted \\
\cline { 2 - 5 } 1 & -1 & -1 & 0.061 & 0.034 \\
2 & -1 & 1 & 0.242 & 0.245 \\
3 & 1 & -1 & 0.151 & 0.145 \\
4 & 1 & 1 & 0.189 & 0.207 \\
5 & -1 & 0 & 0.090 & 0.111 \\
6 & 1 & 0 & 0.171 & 0.148 \\
7 & 0 & -1 & 0.050 & 0.081 \\
8 & 0 & 1 & 0.250 & 0.218
\end{tabular}

Table 6: Measured and predicted $\mathrm{A}_{620}$ values of $\mathrm{Qt} / \mathrm{AA}$ mixtures, determined for individual design points.

\begin{tabular}{ccccc}
\hline Design point & \multicolumn{2}{l}{ Independent variables } & \multicolumn{2}{c}{ Response $\left(\mathbf{A}_{620}\right)$} \\
\cline { 2 - 5 } & $\mathbf{X}_{1}$ & $\mathbf{X}_{2}$ & Observed & Predicted \\
\cline { 2 - 5 } 1 & -1 & -1 & 0.102 & 0.069 \\
2 & -1 & 1 & 0.310 & 0.307 \\
3 & 1 & -1 & 0.704 & 0.701 \\
4 & 1 & 1 & 0.740 & 0.769 \\
5 & -1 & 0 & 0.154 & 0.184 \\
6 & 1 & 0 & 0.761 & 0.730 \\
7 & 0 & -1 & 0.392 & 0.420 \\
8 & 0 & 1 & 0.602 & 0.574 \\
9 & 0 & 0 & 0.500 & 0.493 \\
10 & 0 & 0 & 0.492 & 0.493 \\
\hline
\end{tabular}

IJFS |October 2013 | Volume 2 | pages 238-251 
each case were recorded in the form of threedimensional plots (figures $4-6$ ).

In order to test the validity of the models established, or to point out discrepancies with the linear regression approach, the same hypothesis as above was used (see section 3.1). By replacing in the equation obtained for the AA / Qt mixture (Table 7) the coded values corresponding to $0.1 \mathrm{mM}$ AA and $0.1 \mathrm{mM}$ Qt, the $\mathrm{A}_{620}$ found was 0.368. Similarly, the $\mathrm{A}_{620}$ for the mixtures AA / FA and AA / Hp were 0.153 and 0.083. Thus, the ME for the mixtures of AA / Qt, AA / FA and AA / Hp would be $0.82,0.65$ and 0.61 , respectively. In this case, it can be argued that the interactions in all mixtures tested resulted in antagonism.

\section{Discussion}

In food systems that are deteriorated by peroxyl radicals $\left(\mathrm{R}^{\bullet}\right)$, the "deactivation" of oxidant species by polyphenolic antioxidants $(\mathrm{POH})$ is based on the donation of hydrogen, which interrupts chain reactions:

$$
\mathrm{R}^{\bullet}+\mathrm{POH} \rightarrow \mathrm{R}-\mathrm{H}+\mathrm{PO}^{\bullet}
$$

Phenoxyl radicals $\left(\mathrm{PO}^{\bullet}\right)$ generated following to this reaction may be stabilized through resonance and/or intramolecular hydrogen bonding, as proposed by Bors, Heller, Michel, and Saran (1990) for quercetin, or combine to yield dimerisation products, thus terminating the chain reaction:

$$
\mathrm{PO}^{\bullet}+\mathrm{PO}^{\bullet} \rightarrow \mathrm{PO}-\mathrm{OP}
$$

As pointed out by Brand-Williams, Cuvelier, and Berset (1995), and Bondet, Brand-Williams, and Berset (1997), the efficiency of an antioxidant component to reduce $\mathrm{R}^{\bullet}$ largely depends on its hydrogen-donating ability. Furthermore, it is well-established that polyphenols can be considered as reductants, and "deactivation" of oxidants may be regarded as a redox reaction in which the oxidant is reduced at the expense of the oxidation of antioxidants. In this context, reducing power reflects antioxidant ability. The relevant mechanism of the ferric ion reducing method involves electron transfer from the donor, i.e. a polyphenol $(\mathrm{POH})$, to the TPTZ-Fe(III) complex:

$$
\text { TPTZ-Fe(III) }+\mathrm{POH} \rightarrow \text { TPTZ-Fe(II) }+\mathrm{POH}^{\bullet+}
$$

It has been proposed that in binary mixtures of antioxidants several phenomena might occur, but coupled reactions of regeneration could be taken into consideration to explain the ME observed (Peyrat-Maillard et al., 2003). In this context, the results anticipated could include (i) a synergistic effect if the less efficient antioxidant regenerates the more efficient one, (ii) an antagonistic effect if the more efficient molecule regenerates the less efficient one or (iii) no ME if both antioxidants have the same efficiency. Thus in a given antioxidant assay it is important to rank the substances used, to obtain an order of efficiency, as assumptions on their interactions are based on their relative antioxidant strength.

Using the assay of $\mathrm{P}_{R}$, the order of efficiency found indicated that the most powerful reductant was Qt, followed by AA, FA and $\mathrm{Hp}$. The linear regression approach attempted herein suggested that in equimolar mixtures of each of Qt, FA and Hp with AA, synergistic effect was manifested only with the combination of AA / FA, whereas AA / Qt and AA / Hp combinations resulted in antagonism. Based on this outcome, it was hypothesized that in AA / Qt mixtures, Qt acted towards regenerating oxidized AA, while in AA / Hp mixtures, AA regenerated Hp.

However, in studies regarding interactions in binary antioxidant mixtures, there has been substantial evidence that the regenerating ability of an antioxidant towards another also depends on the relative amounts of the two antioxidants in the mixture. This has been demonstrated in a series of mixtures of flavonoids using $\mathrm{DPPH}^{\bullet}$ and FRAP assays (Hidalgo, Sanchez-Moreno, \& de Pascual-Teresa, 2010), combinations of $\alpha$ tocopherol and AA with various flavonols (Hiramoto, Miura, Ohnuki, Kato, \& Kikugawa, 2002), quercetin with $\alpha$-tocopherol and astaxanthin (Becker, Ntouma, \& Skibsted, 2007), and combinations of $\alpha$-tocopherol and myricetin (Marinova, Toneva, \& Yanishlieva, 2008).

Therefore, by employing equimolar mixtures of AA and a polyphenolic antioxidant, the antioxidant responses recorded might be misleading 
Table 7: Polynomial equations and statistical parameters describing the effect of the independent variables considered for the $\mathrm{P}_{R}$ assay and for all combinations, calculated after implementation of $3 \times 3$ factorial design.

\begin{tabular}{lccc}
\hline $\begin{array}{l}\text { Response } \\
\text { variables }\end{array}$ & $\mathbf{2}^{\text {nd }}$ order polynomial equations & $\boldsymbol{R}^{2}$ & $\boldsymbol{p}$ \\
\hline $\mathrm{FA} / \mathrm{AA}$ & $0.206+0.065 \mathrm{X}_{1}+0.082 \mathrm{X}_{2}-0.036 \mathrm{X}_{1} \mathrm{X}_{2}-0.003 \mathrm{X}_{1}{ }^{2}-0.003 \mathrm{X}_{2}{ }^{2}$ & 0.93 & 0.036 \\
$\mathrm{Hp} / \mathrm{AA}$ & $0.121+0.018 \mathrm{X}_{1}+0.068 \mathrm{X}_{2}-0.036 \mathrm{X}_{1} \mathrm{X}_{2}+0.009 \mathrm{X}_{1}{ }^{2}+0.029 \mathrm{X}_{2}{ }^{2}$ & 0.89 & 0.046 \\
$\mathrm{Qt} / \mathrm{AA}$ & $0.493+0.273 \mathrm{X}_{1}+0.077 \mathrm{X}_{2}-0.043 \mathrm{X}_{1} \mathrm{X}_{2}-0.036 \mathrm{X}_{1}{ }^{2}+0.004 \mathrm{X}_{2}{ }^{2}$ & 0.99 & $<0.001$ \\
\hline
\end{tabular}

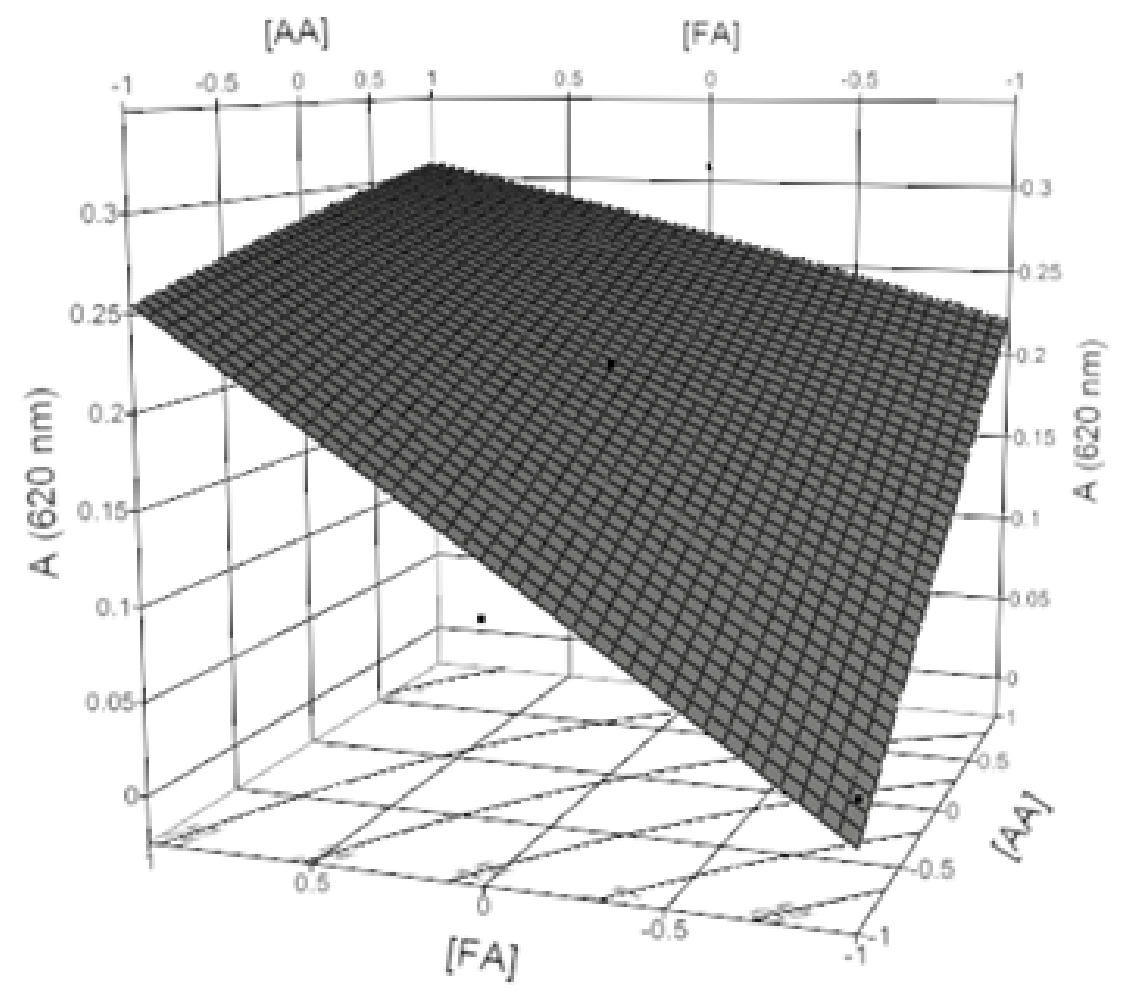

Figure 4: Response-surface plot showing the evolution of $\mathrm{A}_{620}$ upon simultaneous variation of the concentrations of AA and FA. 


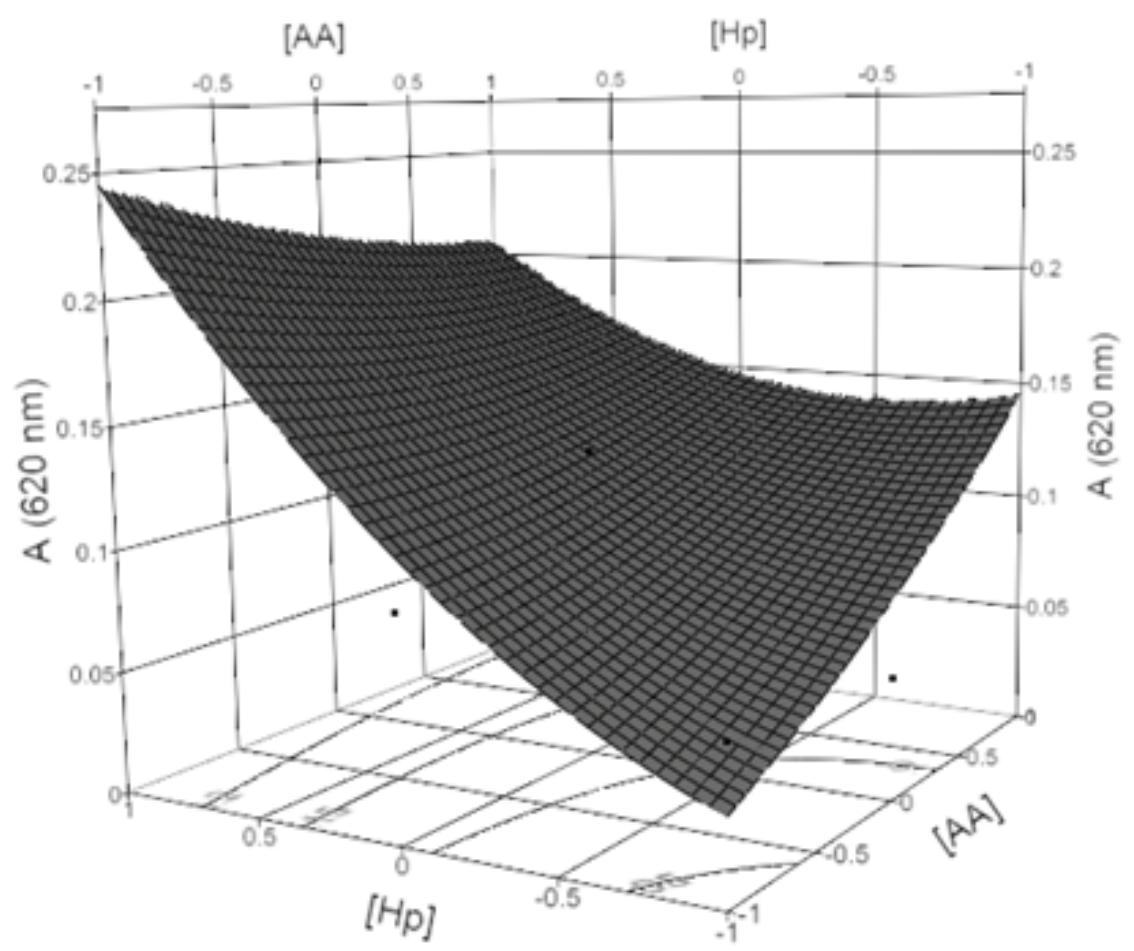

Figure 5: Response-surface plot showing the evolution of $\mathrm{A}_{620}$ upon simultaneous variation of the concentrations of AA and Hp.

with respect to the nature of the effect observed (synergism or antagonism), as maximum efficiency could greatly depend on the relative amounts of the two components interacting. To overcome this unilateral assessment, a factorial design was implemented with the aim of detecting trends in the antioxidant response upon concomitant variation of concentrations of both AA and the polyphenolic antioxidant.

As can be seen in Fig. 4 and Fig. 6, in mixtures of AA / FA and AA / Qt, simultaneous increases in concentrations of both compounds in each mixture resulted in proportional increases in $\mathrm{A}_{620}$, and the theoretically optimal combinations in both cases were equimolar mixtures (Table 8). A more thorough look at the plots in these figures would stress the fact that sharp increases in response $\left(\mathrm{A}_{620}\right)$ occurred when combinations of low amounts of Qt and high amounts of AA were used (Fig. 6), which might suggest that AA interacts with $\mathrm{Fe}^{3+}$, and Qt plays a regenerating role for oxidised AA. For AA / FA mixtures (Fig. 4) this phenomenon was not very pronounced, yet relatively low AA and high FA amounts yielded steeper response increases.

By contrast, in $\mathrm{AA} / \mathrm{Hp}$ mixture a declining tendency was recorded (Fig. 5) when concentration combinations reached the highest limits used, and the best theoretical combination was $0.26 \mathrm{mM} \mathrm{Hp}$ and $0.05 \mathrm{mM} \mathrm{AA}$, which also confirms the interactions presumed between $\mathrm{Hp}$ and AA. Indeed, the fact that the optimal reducing effect was exerted by a mixture that required 5.2fold higher Hp concentration, might indicate that $\mathrm{Hp}$ is primarily involved in $\mathrm{Fe}^{3+}$ reduction, while the low amounts of AA are rather necessary for Hp regeneration.

The rationale is that, as mentioned above, the more efficient molecule regenerates the less efficient one. Taking into account the oxidation po- 


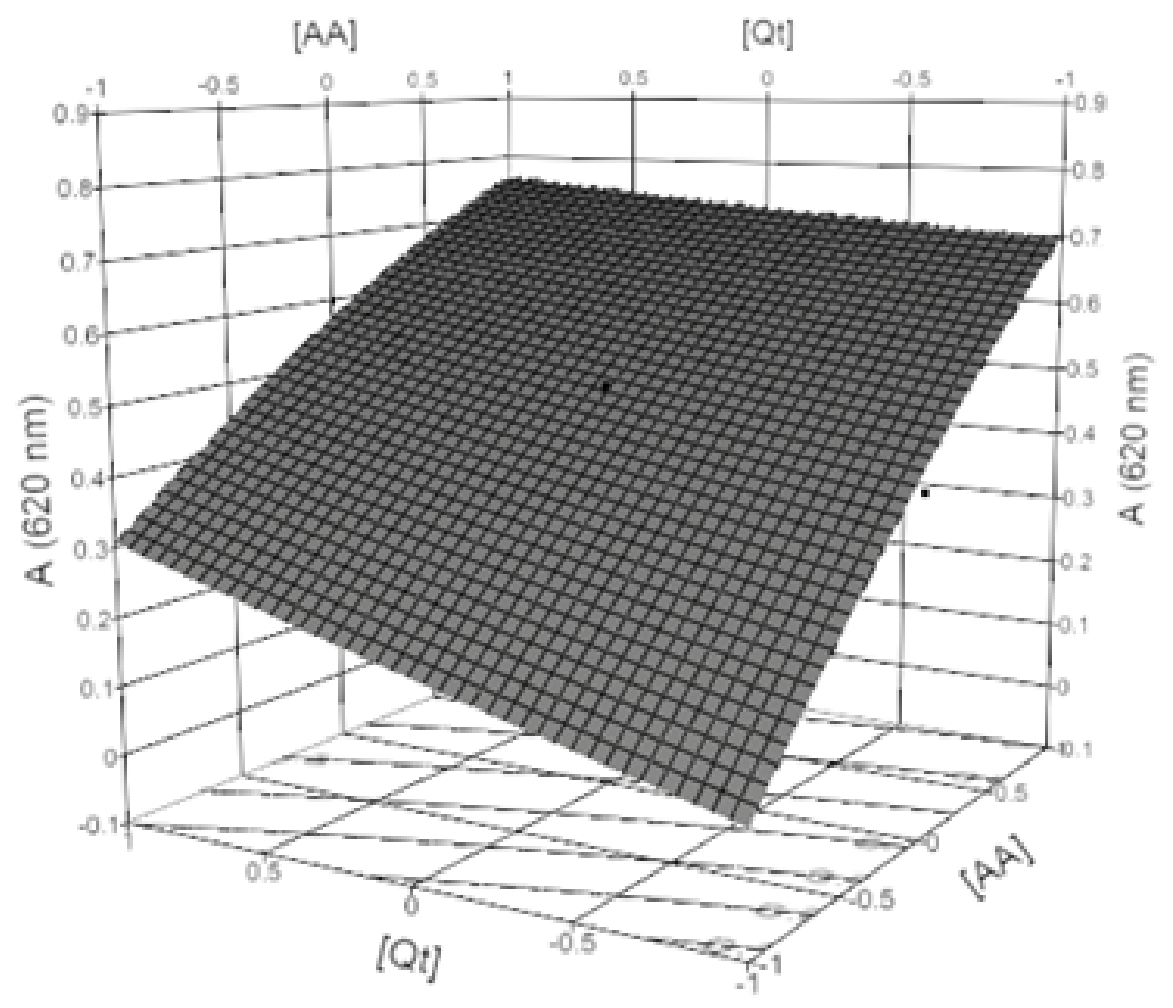

Figure 6: Response-surface plot showing the evolution of $\mathrm{A}_{620}$ upon simultaneous variation of the concentrations of AA and Qt.

tentials, antagonism can be viewed as the regeneration of a compound with higher oxidation potential, to the expense of another with lower oxidation potential, by donation of $\mathrm{H}$ atoms. Hence, regeneration of AA by Qt and AA by Hp resulting in antagonism could occur if Qt had lower oxidation potential than AA. A strong background to support such a hypothesis are studies carried out with cyclic voltametry, where it has been demonstrated that Qt indeed possess lower oxidation potential $(91 \mathrm{mV})$ than AA $(127 \mathrm{mV})$, whereas FA $(350 \mathrm{mV})$ and $\mathrm{Hp}(434 \mathrm{mV})$ significantly higher potential (Roleira et al., 2010; Abou Samra, Chedea, Economou, Calokerinos, \& Kefalas, 2011). Thus, for all combinations tested, the data obtained herein provided sound evidence that the most efficient antioxidant is probably consumed at the expense of the regeneration of the less efficient one, hence the manifestation of antagonistic phenomena. The outcome of the factorial design approach indicated that the phenolic concentration contributed significantly $(\mathrm{p}<0.05)$ to the expression of reducing ability in all mixtures tested (Table 9), but the AA concentration was not significant in the mixture with Hp. It appears that there might be a threshold beyond which the concentration of an antioxidant becomes non-significant with respect to contributing to $\mathrm{Fe}^{3+}$ reduction, owing to more intense antagonism. This assumption, however, remains to be elucidated. 
Reducing Power of Ascorbic Acid / Polyphenol Solutions | 249

Table 8: Optimal, predicted molar ratios and theoretically calculated maximal values for $\mathrm{A}_{620}$, obtained from the implementation of the $3 \times 3$ factorial design.

\begin{tabular}{ccc}
\hline Mixture & Maximal predicted response & Optimal ratio (mM / mM) \\
\hline FA / AA & 0.310 & $0.26 / 0.26$ \\
Hp / AA & 0.245 & $0.26 / 0.05$ \\
Qt / AA & 0.769 & $0.26 / 0.26$ \\
\hline
\end{tabular}

Table 9: $P$-values illustrating the significance of the concentration of AA and the antioxidants, in the mixtures tested by the $3 \times 3$ factorial design. Values were determined deploying one-way ANOVA.

\begin{tabular}{crrrr}
\hline Mixture & {$[\mathbf{Q t}]$} & {$[\mathbf{F A}]$} & {$[\mathbf{H p}]$} & {$[\mathbf{A A}]$} \\
\hline Qt / AA & 0.0072 & - & - & $<0.0001$ \\
FA / AA & - & 0.0051 & - & 0.0114 \\
$\mathrm{Hp} / \mathrm{AA}$ & - & - & 0.0079 & 0.2569 \\
\hline
\end{tabular}

\section{Conclusions}

The response surface methodology used showed that Qt, FA and Hp exhibit antagonism when combined with AA, a fact that can be attributed to the regenerating ability of the most efficient antioxidant at the expense of the less efficient one. It was also emphasised that maximal efficiency in the mixtures tested is a result of an ideal ratio of concentrations of a given polyphenol and AA.

While for AA / Qt and AA / Hp mixtures the outcomes from both linear regression and factorial design approaches were in accordance, pointing to antagonistic effects, the picture obtained for AA / FA is less clear. It is proposed that this system should be further studied by carrying out a factorial design over wider ranges of concentrations, to determine whether there is a breakeven point of the apparently mutual protection between AA and FA.

The approaches attempted in this study questioned investigations carried out by employing binary mixtures of antioxidants, combined at predetermined ratios. The evidence emerged from the investigations performed herein clearly indicates that to ascertain the behaviour of a system composed of two antioxidants, it is indispensable that a factorial design should be established, to enable reliable prediction of the response(s) within appropriate limits. This is particularly crucial for antioxidants that are destined to be added in food matrices, where maximal antioxidant protection is always sought.

\section{References}

Abou Samra, M., Chedea, V. S., Economou, A., Calokerinos, A., \& Kefalas, P. (2011). Antioxidant/prooxidant properties of model phenolic compounds: part i. studies on equimolar mixtures by chemiluminescence and cyclic voltammetry. Food Chemistry, 125(2), 622-629. doi:10.1016/j.foodchem. 2010.08.076

Becker, E. M., Ntouma, G., \& Skibsted, L. H. (2007). Synergism and antagonism between quercetin and other chain-breaking antioxidants in lipid systems of increasing structural organisation. Food Chemistry, 103(4), 1288-1296. doi:10.1016/ j. foodchem.2006.10.034

Benoit, I., Navarro, D., Marnet, N., Rakotomanomana, N., Lesage-Meessen, L., Sigoillot, J.-C., ... Asther, M. (2006). Feruloyl esterases as a tool for the release of phenolic compounds from agroindustrial by-products. Carbohydrate Research, 341(11), 1820-1827. doi:10.1016/ j.carres.2006.04.020

Bondet, V, Brand-Williams, W, \& Berset, C. (1997). Kinetics and mechanisms of antioxidant activity using the dpph* free radical method. Food Science and TechnologyLebensmittel-Wissenschaft \& Technologie, 30(6), 609-615.

Bors, W, Heller, W, Michel, C, \& Saran, M. (1990). Flavonoids as antioxidants - deter- 
mination of radical-scavenging efficiencies. Methods in Enzymology, 186, 343-355.

Brand-Williams, W, Cuvelier, M., \& Berset, C. (1995). Use of a free-radical method to evaluate antioxidant activity. Food Science and Technology-Lebensmittel-Wissenschaft 85 Technologie, 28(1), 25-30.

Choe, E., \& Min, D. B. (2009). Mechanisms of antioxidants in the oxidation of foods. Comprehensive Reviews in Food Science and Food Safety, 8(4), 345-358. doi:10. $1111 / \mathrm{j} .1541-4337.2009 .00085 . x$

Clifford, M. (2000). Chlorogenic acids and other cinnamates - nature, occurrence, dietary burden, absorption and metabolism. Journal of the Science of Food and Agriculture, 80 (7), 1033-1043. doi:10.1002/(SICI)10970010(20000515) 80:7〈1033::AID- JSFA595〉 3.3. CO;2-K

Di Mauro, A, Fallico, B, Passerini, A, \& Maccarone, E. (2000). Waste water from citrus processing as a source of hesperidin by concentration on styrene-divinylbenzene resin. Journal of Agricultural and Food Chemistry, 48(6), 2291-2295. doi:10.1021/ jf99092w

Hidalgo, M., Sanchez-Moreno, C., \& de PascualTeresa, S. (2010). Flavonoid-flavonoid interaction and its effect on their antioxidant activity. Food Chemistry, 121(3), 691-696. doi:10.1016/j.foodchem.2009.12.097

Hiramoto, K., Miura, Y., Ohnuki, G., Kato, T., \& Kikugawa, K. (2002). Are water-soluble natural antioxidants synergistic in combination with $\alpha$;-tocopherol? Journal of Oleo Science, 51(9), 569-576.

Kessler, M, Ubeaud, G, \& Jung, L. (2003). Anti- and pro-oxidant activity of rutin and quercetin derivatives. Journal of Pharmacy and Pharmacology, 55(1), 131-142. doi:10. 1211/002235702559

Krishnaiah, D., Sarbatly, R., \& Nithyanandam, R. (2011). A review of the antioxidant potential of medicinal plant species. Food and Bioproducts Processing, 89(C3), 217-233. doi:10.1016/j.fbp.2010.04.008

Londono-Londono, J., de Lima, V. R., Lara, O., Gil, A., Crecsynski Pasa, T. B., Jaime Arango, G., \& Ramirez Pineda, J. R. (2010). Clean recovery of antioxi- dant flavonoids from citrus peel: optimizing an aqueous ultrasound-assisted extraction method. Food Chemistry, 119(1), 8187. doi:10.1016/j.foodchem.2009.05.075

Makris, D. P., Boskou, G., \& Andrikopoulos, N. K. (2007). Recovery of antioxidant phenolics from white vinification solid by-products employing water/ethanol mixtures. Bioresource Technology, 98(15), 2963-2967. doi:10.1016/j.biortech.2006.10. 003

Marinova, E., Toneva, A., \& Yanishlieva, N. (2008). Synergistic antioxidant effect of alpha-tocopherol and myricetin on the autoxidation of triacylglycerols of sunflower oil. Food Chemistry, 106(2), 628633. doi:10.1016/j.foodchem.2007.06.022

Peyrat-Maillard, M., Cuvelier, M., \& Berset, C. (2003). Antioxidant activity of phenolic compounds in 2,2 '-azobis (2amidinopropane) dihydrochloride (aaph)induced oxidation: synergistic and antagonistic effects. Journal of the American Oil Chemists Society, 80(10), 1007-1012. doi:10.1007/s11746-003-0812-z

Pokorny, J. (2007). Are natural antioxidants better - and safer - than synthetic antioxidants? European Journal of Lipid Science and Technology, 109(8), 629-642. doi:10 . 1002/ejlt.200790023

Prochazkova, D., Bousova, I., \& Wilhelmova, N. (2011). Antioxidant and prooxidant properties of flavonoids. Fitoterapia, 82(4), 513-523. doi:10.1016/j.fitote.2011.01.018

Roleira, F. M. F., Siquet, C., Orru, E., Manuela Garrido, E., Garrido, J., Milhazes, N., ... Borges, F. (2010). Lipophilic phenolic antioxidants: correlation between antioxidant profile, partition coefficients and redox properties. Bioorganic $\& 3$ Medicinal Chemistry, 18(16), 5816-5825. doi:10.1016/j . bmc.2010.06.090

Tilay, A., Bule, M., Kishenkumar, J., \& Annapure, U. (2008). Preparation of ferulic acid from agricultural wastes: its improved extraction and purification. Journal of Agricultural and Food Chemistry, 56 (17), 76447648. doi:10.1021/jf801536t

Tomas-Barberen, F., \& Clifford, M. (2000). Flavanones, chalcones and dihydrochalcones 
Reducing Power of Ascorbic Acid / Polyphenol Solutions | 251

- nature, occurrence and dietary burden.

Journal of the Science of Food and Agriculture, 80(7), 1073-1080. doi:10.1002/

(SICI ) $1097-0010(20000515) 80: 7\langle 1073::$

AID-JSFA568>3.0.CO;2-B 